\title{
USOS CONSUETUDINARIOS, CONFLICTOS ACTUALES Y CONSERVACIÓN EN EL BORDE COSTERO DE CHILOÉ INSULAR ${ }^{1}$
}

\author{
JUAN C. SKEWES*, RICARDO ÁLVAREZ** Y MAGDALENA NAVARRO****
}

\begin{abstract}
RESUMEN
Se describe el modelo consuetudinario prevalente en la ocupación del borde costero de Chiloé insular a partir de información histórica y de observaciones y relatos testimoniales de residentes de comunidades costeras. Analizamos las formas de regulación tradicionales en el acceso a la naturaleza, las que se contrastan con las surgidas a raíz de la expansión de la industria pesquera. Se identifican los rasgos principales del modelo consuetudinario, el que se plasma materialmente en las modalidades que históricamente se emplearon para acceder a las faenas de pesca y recolección de algas y mariscos. La relación mar-tierra, en este modelo, adquiere un carácter especular toda vez que las actividades agrícolas y pesqueras se reflejan recíprocamente. El modelo consuetudinario asegura así integración de las actividades productivas terrestres y marinas y garantiza flexibilidad en el acceso y distribución de los recursos costeros. Con ello se sientan las bases, por una parte, para un modelado recíproco entre las comunidades y el paisaje, y, por la otra, para el despliegue de prácticas de asociatividad que permitían la integración entre los propietarios de los corrales de pesca y quienes se les sumaban en calidad de espectadores de su tarea productiva. La imagen del corral de pesca y el sendero que le une al territorio encarna este modelo. Actualmente, los usos consuetudinarios se ven amenazados por la expansión de las industrias surgidas en torno a la explotación de recursos marinos para el mercado internacional. Frente a esta situación es imperativo propiciar formas de vinculación sustentables entre actores como la recuperación de espacios comunitarios, en un contexto donde se privilegia la privatización y competitividad. El modelo consuetudinario, montado sobre la base de la relación especular mar-tierra provee principios de organización que permiten orientar acciones de planificación territorial inclusivas de la pluralidad de actores. Se concluye subrayando la posibilidad de recuperar los principios integradores involucrados en las prácticas consuetudinarias tanto para la conservación de especies amenazadas como para favorecer el manejo sustentable del medio.
\end{abstract}

PALABRAS CLAVE: Chiloé, tradicional, recursos, áreas costeras, pesca, ordenamiento territorial.

1 Esta publicación se sustenta en los trabajos de campo e investigación realizados en el marco del Estudio Investigación para el Desarrollo del Área Marina Costera Protegida Chiloé (CÓDIGO BIP № 30040215-0 ID 1857-17 LP07), con el apoyo de la ONG Centro Ballena Azul y World Wildlife Fund - WWF.

* Universidad Alberto Hurtado, Departamento de Antropología, jskewes@ahurtado.cl, Cienfuegos 41, Santiago.

* Antropólogo, taijataf@gmail.com.

*s* Antropóloga, magda.np@gmail.com. 


\title{
CUSTOMARY USES, CURRENT CONFLICTS AND CONSERVATION OF THE COASTAL AREAS OF INSULAR CHILOÉ
}

\begin{abstract}
Based on historical sources and observation and testimonies of local residents, the traditional pattern of resource use in the coastal area of Chiloé is described. This article analyzes the traditional access to natural resources that contrasts with those arisen from the expansion of the fishing industry. The main features of the traditional pattern - embodied in the material culture - are identified in relation to fishing and seaweed and seafood gathering. The relation between land and ocean, in this pattern, acquires a mirror effect insofar agriculture and fishing activities reflect each other. The traditional pattern assures the integration of ocean and land-based productive activities, while guaranteeing flexibility and access to the coastal resources. Thus bases are laid for a mutual modeling between communities and the landscape and for the deployment of associative practices that allow the integration of the fishing corrals' owners and those who from the outside contribute to the fishing activity. The image of the fishing corral and the walkway that connects it to the land embodies this pattern. Currently, the traditional patterns are threatened by the industrial expansion associated with the exploitation of coastal resources for the international market. Faced with this situation, it is imperative to stimulate ways of sustainable integration between the actors and their own economic space in a context where, on the contrary, what is stressed is privatization and competiveness. The traditional pattern, based on the mirror relation land-ocean provides organizing principles that guide the territorial management with the inclusion of a variety of actors. The recovery of the organizing principles embodied in traditional practices is suggested as a means both for the conservation of threatened species and for the sustainable use of the environment.
\end{abstract}

KEY WORDS: Chiloé, traditional, resource, coastal areas, fishing, territorial management.

\section{INTRODUCCIÓN}

El estudio de los patrones tradicionales de uso de los recursos costeros en la isla de Chiloé provee un marco de referencia para las acciones que promueven la sustentabilidad tanto de las comunidades locales como de las especies que habitan el territorio. Este estudio se plantea desde una perspectiva que interpreta las prácticas consuetudinarias y el impacto que para ellas ha significado la interacción con otros actores que no comparten sus formas de relacionarse con el medio. El análisis se hace sobre la base de las constataciones hechas en ocho comunidades costeras de Chiloé insular, identificándose los núcleos principales de conflicto entre usos del borde costero y sus consecuencias para las poblaciones, para plantear, a partir de este análisis, las condiciones mínimas de pertinencia que podrían orientar una estrategia de protección y uso sustentable de los recursos naturales y de ordenamiento territorial.

Para la realización de este estudio se consideraron fuentes históricas y etnográficas a fin de caracterizar un modelo consuetudinario de vinculación entre el mar y la tierra. Este modelo, que tiene un carácter de tipo ideal, resume los principales atributos que, a partir del relato testimonial y del registro material, surgen como garantes de la continuidad temporal de comunidades humanas y no humanas que, bajo las actuales condiciones de producción, se ven amenazadas en su sustentabilidad.

En la identificación de las características del modelo consuetudinario se recurre a una visión teórica que corresponde a un materialismo vital, esto es, a una visión en la que los seres humanos son vistos en su relación de mutua dependencia con los no humanos $y$, sobre todo, de poderes equivalentes en la generación de los procesos en los que ambos participan. Esta visión inspirada por autores como Tim Ingold (2011) y Bruno Latour (2001) se integra a la ecología política que, a partir de los noventa adquiere notoriedad en la reflexión acerca de los procesos biosociales e históricos. De especial relevancia para este estudio es la discusión acerca de la regulación de los accesos a los recursos naturales (o 
de las condiciones de encuentro entre humanos y no humanos), toda vez que una parte significativa de la actual práctica de conservación esta marcadamente influida por la idea de la tragedia de los comunes (Hardin 1968), imagen que, a la luz de las prácticas descritas en lo que sigue, queda en entredicho.

El recorrido etnohistórico y etnográfico relativo al complejo regional constituido por el archipiélago de Chiloé invita a reconsiderar la mirada prevalente respecto al carácter insular y no relacional del área: tanto los procesos históricos de las poblaciones humanas como de las especies no humanas sugieren un entrelazamiento permanente del conjunto marítimo y territorial comprendido entre las actuales décima y decimoprimera regiones. A través de la observación etnográfica efectuada durante el año 2009 en las localidades de Coñimo, Guaipulli, Guapilacuy, isla Laitec, punta Chilen, Cucao, Huente Caulín, y Wuenke Caulín, se ha podido constatar la continuidad parcial de los referidos procesos históricos, a la vez que se han advertido los impactos involucrados por la expansión del mercado de los recursos del mar, especialmente la extracción excesiva de recursos bentónicos, de algas y el explosivo aumento de la salmonicultura y mitilicultura.

El examen del modelo consuetudinario permite, a través de la identificación de sus rasgos dominantes, proponer orientaciones para aquellas intervenciones que procuran contribuir a la sustentabilidad de las poblaciones humanas y demás especies del área. Estos rasgos, convenientemente refrendados por el registro histórico y etnográfico, se refieren al vínculo mar-tierra, a la flexibilidad en el acceso y distribución de los recursos, y a las prácticas de asociatividad prevalentes en el medio chilote.

\section{LA COMPLEJIDAD DE LAS OCUPACIONES LITORALEÑAS}

El litoral es un espacio de encuentro para poblaciones humanas y no humanas que se condicionan recíprocamente en su existencia. La comprensión de estos procesos no puede abstraerse del hecho de la materialidad de los humanos y su necesario $y$ permanente intercambio con el medio que hace posible su existencia como especie (Bennet 2010). La noción de agencia, actuante tal cual es formulada por Bruno Latour (op.cit.), deja de ser en esta perspectiva una prerrogativa humana y se torna universal entre los seres y cuerpos que constituyen el planeta. La noción misma de especie como algo animado en oposición a los seres "inanimados" queda fuera del cálculo contemporáneo: la voluntad de ser también es prerrogativa universal más allá incluso de los procesos biológicos.

Esta visión general coincide con el análisis de la ecología política propuesta por autores como Arturo Escobar (1999), Enrique Leff (2003) y otros. En lo sustantivo, estos autores enfatizan las relaciones de poder que están en la base de lo que otrora se concibiese como equilibrio ecológico. Más que un balance establecido per se, tales equilibrios son mejor entendidos como el producto histórico que cada época ha podido agenciar a través de la interacción entre seres humanos desigualmente posicionados y los seres no humanos con los que se vinculan. James O'Connor (1998), por ejemplo, postula una segunda contradicción del capitalismo, a saber, el desmantelamiento que el afán de lucro provoca en las condiciones de producción (la naturaleza, la fuerza de trabajo y la infraestructura comunitaria) que constituyen la base de su propia realización. La producción capitalista no produce tales condiciones sino más bien las transa como bienes ficticios. La expansión del capital determina la aceleración en el uso de estos recursos, provocando un incremento en los precios y poniendo en jaque la propia producción capitalista (ver también Bedoya y Martínez 2000).

La prospección de modalidades alternativas de vinculación sociedad-naturaleza pasa por la investigación de los impactos que la expansión capitalista ha tenido en economías no capitalistas y en el estudio etnográfico de ensamblaje naturaleza-sociedad en otras culturas, superando visiones románticas acerca del carácter supuestamente ecológico de aquellas sociedades (Weeratunge et.al. 2000: 249). Schmink y Wood (1987) contribuyen a esclarecer las avenidas que la investigación de los impactos del capitalismo a nivel local debe transitar. Estos autores demuestran que la presión ejercida sobre las comunidades locales lleva desde la reproducción simple a una economía de producción ampliada y, con ello, a una mayor degradación del entorno. El estado, en un contexto de frontera, por su indefinición y favoritismo hacia grupos empresariales, deja abiertas las puertas para una explotación ilimitada de los recursos (ibid: 51). La situación descrita da cuenta de la doble complejidad de los procesos locales: su vinculación con el 
entorno regional e internacional y su complejidad interna, en términos de los intereses dispares que se despliegan en la población.

La ocupación de las zonas costeras ha sido por lo general considerada de libre acceso aun cuando de hecho han existido formas de regularlo que se definen por los derechos de uso. En efecto, Durrenberger y Palsson (1987) sugieren que aquello que cabe investigar y discutir se refiere a las formas como se ha organizado éste. El mar no necesariamente es tenido como propiedad común y no hay distinción sistemática entre conceptos de propiedad, territorialidad, acceso, y control de los territorios marinos. La literatura citada por estos autores pone de relieve las múltiples posibilidades que las comunidades locales han establecido para la ocupación y uso de los territorios marítimos.

Corresponde, en consecuencia, examinar los usos que se hace de los recursos costeros a partir de los sistemas más amplios y no sólo en términos de la actividad misma. De aquí se abren posibilidades de entender, por ejemplo, la actividad pesquera como una extensión de la actividad recolectora o, incluso, agrícola, correspondiendo, en consecuencia, examinar en términos de la realidad local las formas como se ha constituido el acceso al medio litoral (ibid).

\section{EL BORDE COSTERO DE CHILOÉ}

El área de Chiloé - Corcovado - Chonos corresponde a una vasta región de carácter archipielágico donde los hitos insulares y continentales se entrelazan por la constante actividad humana y por los ciclos migratorios y movilidad de otras especies. De aquí que resulte conveniente definir el área como un medio integrado en el que tierra y mar se interrelacionan tanto por la actividad humana como no humana. Hace más de 6.000 años AP se inicia el poblamiento litoral de Chiloé y los canales australes, como un proceso que no se detiene y a través del que se ocupan todas las islas, fiordos y costas orientales y occidentales de esta región. Este proceso sienta bases profundas para comprender el modelo consuetudinario que se analiza en este artículo.

Aún no está claro si el poblamiento marítimo se originó en el sur de Chile a partir de la transición de poblaciones de cazadores recolectores terrestres a cazadores recolectores marítimos, o si existen otras posibilidades aun no identificadas. Fueron familias de canoeros, esto es, poblaciones que daban un uso estratégico a embarcaciones simples con las que se desplazaban a fin de asegurar su reproducción y continuidad, quienes entretejieron el espacio regional. El registro arqueológico para estas ocupaciones canoeras es amplio y abarca la casi totalidad de los fiordos y canales establecidos desde el seno de Reloncaví hasta el cabo de Hornos, y evidencia una estrategia de vida eficaz a través del tiempo, en la que los procedimientos de recolección y captura se basaban en el uso de proyectiles, arpones, redes de fibras vegetales y aparejos de pesca tales como corrales de piedras y varas, y la recolección intensiva de orilla, destinados al consumo inmediato de los productos obtenidos, patrón que se reitera en nuevos contextos históricos (Aspillaga et al. 1995; Gaete et al. 2004; Legoupil 2005; Ocampo y Rivas 2004; Porter 1995: 82; Rivas et al. 2000).

La llegada de pueblos alfareros de carácter semisedentario a Chiloé, hacia el año 1.400 aproximadamente, cambia el escenario (Aldunate, 1996; Menghin, 1962). Estos nuevos habitantes poseían una economía basada en la horticultura y, en tiempos tardíos aparentemente, ganadería menor de camélidos, y un sistema de organización territorial y social mucho más complejo que el de los canoeros. Esto les permitió abordar no sólo el borde costero del archipiélago, sino además el interior de la Isla Grande e islas menores, desplegando con ello nuevas estrategias de aprovechamiento de los recursos locales. El control de los vegetales y su modificación intencional para generar variedades más productivas en especies como la papa no provocó un deterioro en el ambiente local y permitió continuar con una relación sociedad-entorno basada en el autosustento.

La temprana ocupación hispana en el siglo XVI se encarna en pequeñas plazas urbanizadas (lo que permitía la reducción de las familias y militares hispanos en un centro demarcado) y en la instauración de la encomienda como sistema de explotación de las poblaciones indígenas y de los recursos: los Williche fueron rápidamente forzados a trabajar con el fin de abastecer a los españoles radicados en la zona, o enviados a trabajados forzados a otras regiones del país. En ausencia de riquezas minerales, la producción española no tardó en concentrarse en la explotación del alerce (Fitzroya cupressoides) para ser exportado principalmente al Virreinato del 
Perú y su proyecto urbanizador rápidamente dio paso a la dispersión espacial de las familias hispanas a manera de cómo vivían los Williche.

Hacia finales del siglo XVIII, ya abolida la encomienda, las familias hispanas se habían adaptado hasta el grado de apropiarse de la cultura indígena haciéndola suya, e incorporándole elementos propios, dando pie al mestizaje que caracteriza hoy en día a la población chilota y donde tanto elementos coloniales europeos como indígenas son transversales a toda la sociedad. Esto ya se evidenciaba 100 años antes, a través de este comentario, realizado por españoles refiriéndose a la sociedad castiza de Chiloé hacia 1611: ... todos los españoles saben aquella lengua mejor que la castellana, por el mucho trato que tienen con los indios (Olivares 1874: 370).

El aislamiento del territorio persistió a pesar de su "chilenización" a principios del siglo XIX, lo que permitió que muchas costumbres y tradiciones coloniales siguiesen practicándose con regularidad. La tala de bosques continuó siendo relevante, sobre todo en torno al ciprés (Pilgerodendron uviferum) y alerce (Fitzroya cupressoides), apareciendo además nuevos mercados que motivaron la caza intensiva de mamíferos marinos, principalmente cetáceos, lobos marinos y nutrias, mermando drásticamente sus poblaciones. La sociedad local inicia un proceso de migración hacia las salitreras y balleneras en el norte de Chile, a las cosechas de trigo y papas de la provincia de Osorno, y hacia la Patagonia chileno-argentina, que se intensificará durante la primera mitad del siglo siguiente, ante la precariedad económica que agobió a la Provincia. Por otro lado, los territorios continentales y canales más australes siguieron estando despoblados, salvo por los pequeños grupos de hacheros o cazadores de pieles.

Es el siglo XX el que marca la intensificación de la extracción excesiva de los recursos, sobre todo las dos últimas décadas de éste. Durante la primera mitad los usos para con el maritorio son casi en su totalidad consuetudinarios, con poblaciones chilotas que se trasladan durante meses hacia Las Guaitecas y canales más australes, y residentes ribereños que aplican las mismas estrategias de sus antepasados. Pero para la segunda mitad esta situación cambia. Comienza a madurar una lógica de pesca y recolección mucho más intensa que en el pasado, iniciándose una desvinculación cada vez más significativa entre la cultura local y el entorno, el que adquiere forma, en este contexto, de "recurso económico".

Fruto de los procesos contemporáneos en el litoral de Chiloé se advierten, de modo esquemático, dos dinámicas económicas que conviven conflictivamente: 1) Poblaciones que aplican usos consuetudinarios: campesinos y ribereños que desarrollan actividades de raigambre histórica, con aplicación de métodos sencillos, una alta diversidad de oficios distribuidos estacionalmente y alta movilidad espacial (que combina tierra-mar constantemente), y 2) industria pesquera-acuícola / pesca artesanal que abastece a la industria y poblaciones asalariadas ligadas a la industria. Se advierte una separación clara entre industria y pesca-asalariados. Quienes aplican usos consuetudinarios tienen poca o nula incidencia en la toma de decisiones sobre el maritorio, mientras que los segundos se encuentran en constantes negociaciones, con pesos y resultados desiguales, respecto al destino de los espacios marinos y sus recursos. Durante la historia reciente los primeros han mantenido un patrón de migración constante hacia el segundo grupo: pesca artesanal y asalariados.

Las actividades pesqueras, en claro contraste con la agricultura, representan el sector más dinámico de la economía regional, presentando la X región, la mayor variedad de actividades de este rubro a lo largo del país. El crecimiento de estas actividades es evidente a lo largo del tiempo: ejemplo de lo anterior es el incremento en un $37 \%$ de la flota artesanal de la X región entre los años 2001 a 2008. En cuanto al número de plantas, la región de Los Lagos posee la concentración más significativa a nivel nacional con un 32\% (155 de las 482 plantas existentes). A estas cifras deben sumarse las intensas actividades desarrolladas en el ámbito de la recolección de algas y mariscos. Adicionalmente, la actividad acuícola, principalmente la salmonicultura, creció de forma sostenida hasta la aparición del virus ISA. Esto causó una fuerte crisis en determinados sectores económicos locales que tuvieron que absorber las altas tasas de desocupación surgidas a raíz del cierre de numerosos centros de cultivo. El aumento significativo del número de concesiones ha causado múltiples problemas asociados a su masificación, entre ellos: contaminación, grandes extensiones de espacios costeros ocupados por cultivos y colectores (SERNAPESCA 2001, 2007, 2008). 


\section{EL PATRÓN CONSUETUDINARIO}

La observación sistemática de las prácticas actuales e históricas de las comunidades litorales de Chiloé deja en evidencia que la separación tierra-mar es parte de un hábito de pensamiento occidental más que un hecho habitual de la vida social local. En efecto, una comprensión pertinente de los patrones consuetudinarios del uso del litoral chilote exige entender las actividades marítimas como una prolongación y un reflejo de la actividad terrestre y vice versa. La relación es de carácter especular, esto es, las actividades productivas se reflejan unas a otras, estableciendo entre si soluciones de continuidad.

En la ocupación litoraleña se discierne un patrón de vinculación de las comunidades de Chiloé (Ver
Figura 1) que se asocia a la posibilidad de articular las actividades terrestres con las marítimas. Los enlaces que se producen entre estos espacios tienen, en las prácticas consuetudinarias, el carácter de eslabonamientos a los que concurren - simultáneamente - las unidades sociales, las actividades tecnológicas y los espacios en que ellas se desenvuelven. Estos eslabonamientos permiten, en un sentido, proyectar hacia el medio marítimo las artes productivas del medio terrestre (agricultura, recolección y crianza), y, en sentido inverso, revertir hacia las unidades sociales los productos de la actividad marítima. Es importante subrayar que, bajo condiciones de intervención externa son, justamente, estos enlaces los que se debilitan, tornando vulnerables tanto a las comunidades humanas como a las especies con que ellas se relacionan.

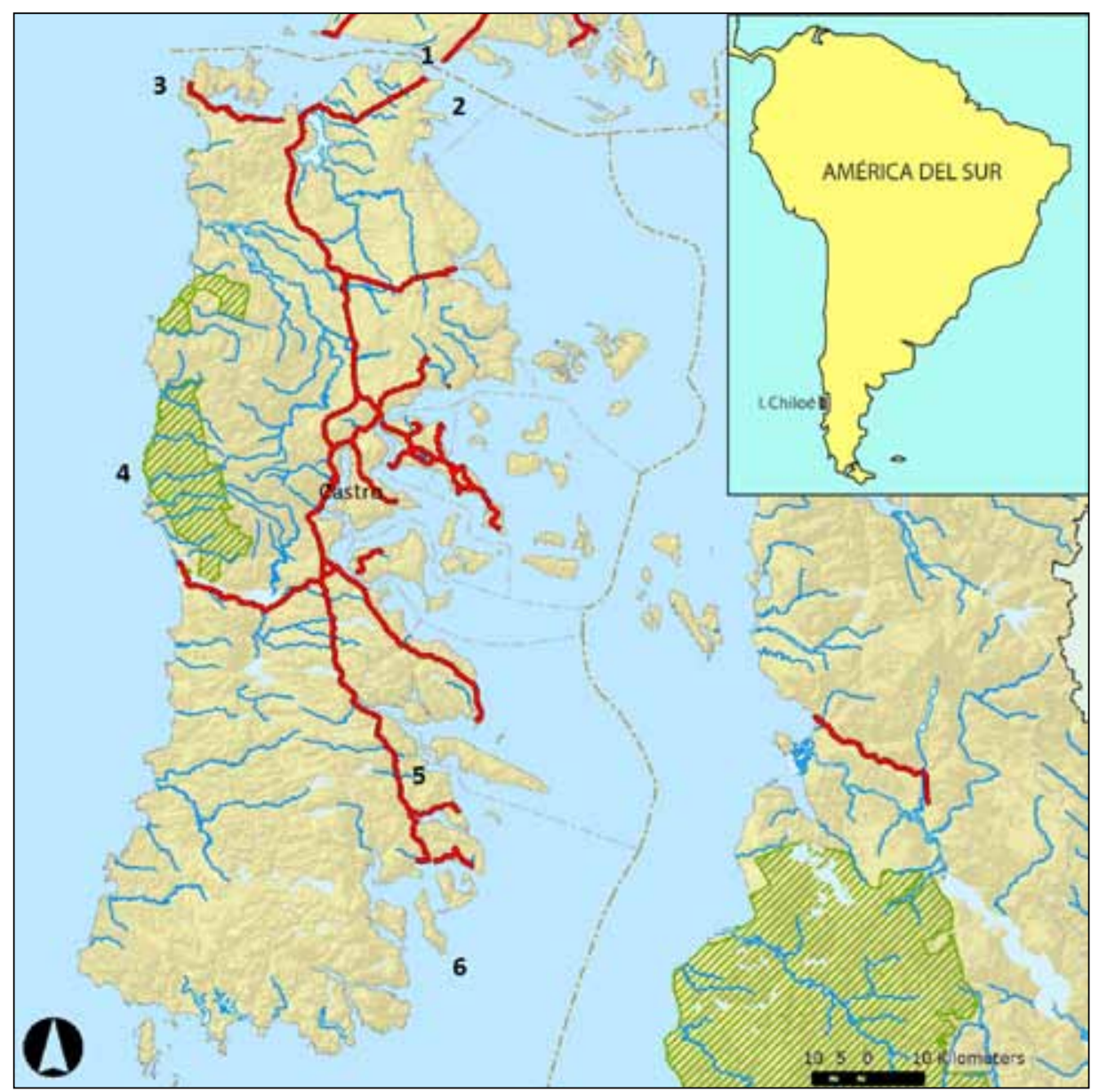

Fig. 1. Archipiélago de Chiloé: Localidades visitadas (1) Wenke Caulín y Wente Caulín; (2) Coñimó y Punta Chilen; (3) Huapi Lacuy; (4) Cucao; (5) Guaipulli; (6) Isla Laitec. Fuente: Elaboración propia en base a cartografía del Ministerio de Obras Públicas (http://geoportal.mop.gov.cl/vialidad/ (5 de diciembre de 2011) e investigación para Desarrollo de Área Marina Costera Protegida Chiloé-Palena-Guaitecas (Hucke et.al. 2010). 
Las estrategias productivas de estas comunidades exhiben dos componentes: el primero es el de la diversificación de la base económica con una división del trabajo tanto social como estacional. El segundo concierne a las prácticas asociativas que permiten regular el acceso a los recursos del mar. Otro aspecto que merece atención, a partir de la observación empírica, es el de los flujos poblacionales. La existencia social en la Isla se basa en una constante vinculación con territorios próximos y distantes a los que, a través de rutas marítimas y terrestres, se accede tanto con fines de empleo como de comercio y trueque, y de los cuales también se depende. Estos circuitos son igualmente transitados por las especies no humanas con las que se establecen relaciones de naturaleza diversa.

Modos consuetudinarios de vincular mar y tierra

El enlace entre mar y tierra adquiere su forma material a través de los senderos de bajamar, los que hoy han menguado su presencia, lo que es sintomático de la desvinculación producida entre actividades que históricamente se mantenían integradas (Ver Figura 2 Izq. - Figura 2 Der.). El acceso a la pesca no se limitaba a las embarcaciones sino también se hacía por tierra, a pie. La posibilidad de hacerlo se asocia directamente a la abundancia de recursos.

La existencia de estos senderos constituye el testimonio material de un vínculo que tuvo un carácter paradigmático para la organización de la tarea productiva. Los ámbitos involucrados por estos senderos ilustran el modelo consuetudinario. En efecto, los "desechos" o huellas que comunican el interior con la costa constituyen el puente que antaño vinculaba a los usuarios de las tierras litorales con sus corrales de pesca, varaderos y zonas de recolección o mariscadura, incluyendo prácticas religiosas.

Los corrales de pesca, tanto de piedra como de varas trenzadas, eran, en muchas de estas comunidades, el hito principal en la organización territorial de la zona litoral, uno de los aspectos cruciales del modelo consuetudinario (Ver Figura 3 Der.). El uso de estos corrales es milenario y su distribución es mundial, por lo que no es extraño que, a la llegada de los españoles al territorio, estas estructuras hayan sido rápidamente reconocidas, como lo demuestra el relato de Gerónimo de Vivar de 1558: Halláronse sardinas de las que llaman en nuestra España arencadas y ansí se halló el arte de aquellos corrales con que la toman en rota (Vivar 1970), refiriéndose con ello a los corrales de muros que caracterizan aun hoy en día a dicha zona de España. Para el territorio chono también se identifica esta práctica tempranamente, refiriendo que usan unos corrales de ramas espesas o de piedra que suelen hacer en las mismas ensenadas (Diego de Torres [s.XVII], en Cárdenas 1991: 107) y que para pescar hacen quando el mar está en total vaciante unos grandes cercos formados con estacas y entretexidos con ramas. ... hay ocasiones que sacan de uno de estos cercos, que ellos llaman Corrales, 500 ó mas Róbalos (González de Agüero 1791: 70-71)².

2 En los textos históricos hemos conservado la caligrafía original.

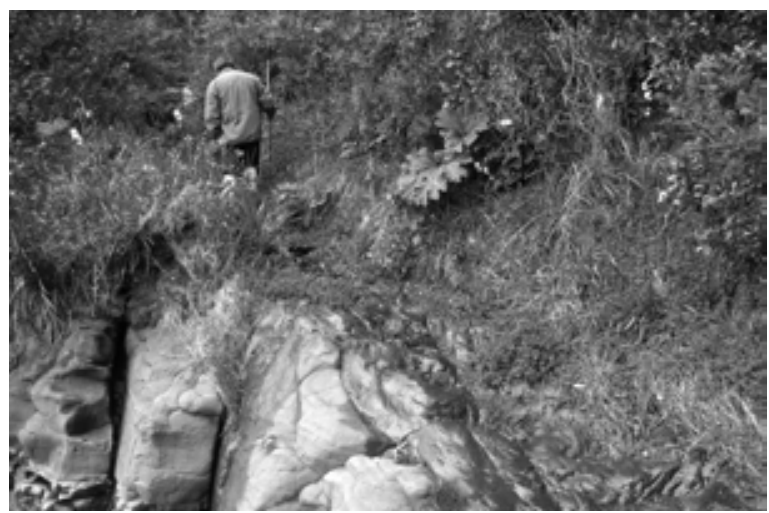

Fig. 2. Izquierda: Sendero de bajamar. Comunidad indígena Tweo de Coldita, comuna de Quellón (Fotografía: R. Álvarez 2009). Derecha: sendero terrestre que comunica tierramar ("desecho"), Wentetique, comuna de Ancud (Fotografía: R. Álvarez 2009). 
En el siglo XVIII, Lázaro de Ribera (1897: 7) da cuenta del uso de aquella técnica: Cuando aquellos isleños quieren hacer una pesca considerable de ellos - róbalos-eligen un estero angosto, el cual lo cierran por medio de una estacada vertical dejando un espacio de pulgada i media o dos de estaca a estaca cuya altura la proporcionan de modo que el flujo de la mar pase por encima. Luego que empiesa a declinar la marea se vé, con nó poca diversion de los circunstantes, toda la playa cubierta de pescado de varias especies, siendo siempre el róbalo escede en número a los demás (Ribera ob.cit.: 7). El corralito de pesca que se hace al costado de un corral más grande. Este corralito contiene un aparato de quila [Chusquea quila] en forma de embudo, con el cual se cogen los peces (Cavada 1914: 365).

En el archipiélago se aplicó masivamente un rito llamado trepute que permitía asegurar una buena pesca con corral y cuya práctica involucraba a pougtenes, quienes, a diferencia de los machis, cumplían un rol poco esclarecido dada la escasa información actualmente obtenible. Entre sus roles estaba el "arreglar" los corrales de pesca y asegurar el éxito de la captura por medio de procedimientos mágicos. Según cuenta don Armando Bahamonde, había que conseguir un curioso para arreglar el corral. El curioso traía algunas maderas como laurel (Laurelia sempervirens) y palotaique y, en ocasiones, una lagartija amarrada para proteger al corral de los maleficios que pudieran causar quienes tuvieran envidia otros que tenían envidia, o también para salvarse del cuchivilu, el cerdo mitológico que derribaba el corral cada cierto tiempo. Para atraer los preces, el curioso dejaba atada la lagartija en el corral hasta que subiera la marea. El experto, después de pronunciar algunas oraciones, en un lenguaje mágico, empezaba a pegar, a chicotear, al corral por todos lados y luego decía: "Bueno he terminado", y se chicoteaba a sí mismo. La ceremonia terminaba con una comida muy confidencial con quienes habían hecho el arreglo: podía ocurrir que el curioso no fuese bien visto y que los participantes de otro corral fueran a a buscar a otro curioso. De hecho se producía una cierta rivalidad entre ellos. (Álvarez et.al. 2008: 158).

Estos corrales, construidos de piedra o varas trenzadas, pertenecían a una familia que lo utilizaba para su autoconsumo, venta menor, y obsequio y/o intercambio con los vecinos. Su abundancia es altamente significativa en el archipiélago de Chiloé, existiendo comunidades, como la de Coñimo, donde su protección (a través de la ley de Monumentos Nacionales №17.288) ha sido fortalecida, al declararlos monumento histórico.

Son abundantes también los varaderos de canoa, destinados a encallar las embarcaciones desde tiempos precolombinos, originalmente canoas de tablones o piezas cosidas, posteriormente bongos (canoas monóxilas) y, en tiempos históricos, goletas y embarcaciones modernas. Espacialmente su presencia se nota por la limpieza de guijarros y piedras en determinados sectores de la costa, asegurándose de esta manera de no dañar el casco de la embarcación (Figura 3 Izq.).

Existían, además de los corrales, otras prácticas de pesca. Don Olegario de Chanquín recuerda: Yo siendo chico, tendría unos 18 años me llevaron los tíos a la pesca, a este río, ... y el mar lleno subía poquito, poquito y nada ... Después dijeron

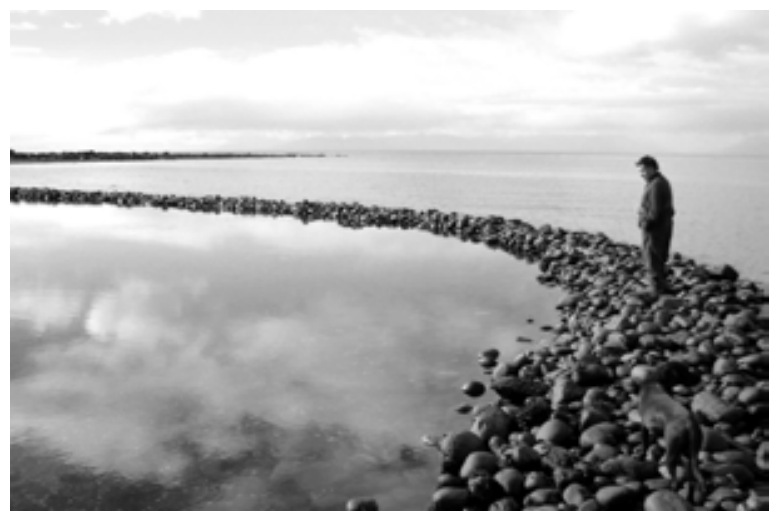

Fig. 3. Izquierda: Varadero de canoas, Coñimó, comuna de Ancud (Fotografía: R. Álvarez 2009). Derecha: Corral de pesca en isla Caguach, familia Peranchiguay comuna de Quinchao (Fotografía: R. Álvarez 2008). 
botemos las redes no más, ya no va a crecer más, cruzaron las redes en el río. Y se fueron dos vareros, uno de este lado y el otro del otro, dos vareros. Pero, jcristianito de Dios! Cuando bajó ese cardumen de pescados, no se pudo sacar las redes, quedaría más o menos medio metro de róbalo, iy cada róbalo!. La relación establecida a través de los corrales, senderos y varaderos constituye el núcleo marítimo de la actividad histórica y se complementa con la recolección y cultivo de algas y con la mariscadura. Este núcleo retroalimenta a las poblaciones del interior a través de sistemas de intercambio, trueque y combinación de actividades productivas, produciéndose un verdadero eslabonamiento en un sentido y otro.

\section{La regulación del acceso a los recursos del mar}

El acceso a los recursos del borde de mar no era libre en el sentido planteado por la "tragedia de los comunes". El modelo consuetudinario garantizaba la precedencia en términos del uso y habilitación que se hacía de la costa. Semejante regulación, no obstante, no se planteaba de modo excluyente $y$, por el contrario, aseguraba por la vía de un eslabonamiento la provisión de las poblaciones más alejadas de la costa, como veremos más adelante.

La regulación del acceso involucraba aspectos normativos y religioso-rituales observados por la comunidad local. El recurso, desde esta perspectiva, se entendía como la base para el sustento del medio familiar. La relación con la naturaleza se fundaba en el valor de uso, tal como se desprende de las observaciones de un cronista de fines del siglo XIX:

Dado el poco espiritu mercantil i previsor del chilote, no es de estrañar que no piense en establecer viveros, en que depositar lo sobrante de sus mariscos, para poder venderlos a mejor precio en las épocas de pobreza, ... surtiendo asi a los pueblos cercanos o a los vapores de la carrera. Existen [...] unos cuantos viveros o cholchenes como el que posee en Dalcahue el señor Silvestre Navarro pero su objeto no es el de servir fines comerciales, sino provee su mesa en cualquier momento i en todas las epocas del año. La construccion es la mas sencilla i natural del mundo, pues esta basada en el curso de las corrientes, que limpian el molusco, haciendole engordar i dandole un sabor mas agradable (Weber 1903: 100).
En la mariscadura de orilla, es importante advertir el uso masivo de apozamientos, hoy prohibidos legalmente, al igual que los corrales de pesca, los que eran respetados por todos y de cuya práctica se tiene memoria reciente: Cuando conocí el quillín como le llamábamos, un canasto grande era porque el canasto grande se llenaba que era un medio saco, digámoslo así, y nosotros en esos años eso no lo subíamos a nuestras casas sino que lo hacíamos cholchen, lo dejábamos hecho el cholchén [...] Es una pozada de mariscos que hacía uno, se apozaba como le decimos nosotros ahora, y eso ninguno se lo robaba. Si lo quería vender ese hombre, o sino lo subía con bueyes y hacía su curanto".

La técnica del apozamiento, desde la perspectiva especular se revierte en tierra. El luche (Porphyra columbina) era sometido a una suerte de reverso estructural en relación a las técnicas aplicadas al molusco: que haga un hoyo en la tierra, y que haga un fuego, entonces ahí poníamos las hojas de pangue (Gunnera chilensis Lam) que le dicen, la nalca, las hojas esas, y encima se extendía el luche (Porphyra spp), y de ahí se tapaba y se le ponían las champas calurositas encima y se dejaba ahí. Cuando ya se calculaba que estaba cocido se sacaba", recuerda una vecina de Cucao. Hoy en día el luche se prepara dentro de tachos de metal puestos dentro del horno. El curanto puede ser tenido como la expresión paradigmática por excelencia del vínculo tierra-mar, técnica que se emplea sea para la conservación de lo recolectado (al ser ahumado y secado en sartas después del curanteo), o para el consumo, en cuyo caso concurren como alimento los productos de tierra y mar.

$\mathrm{Al}$ igual que con el uso de corrales, antiguamente existían mitos que regulaban el uso de los bancos de mariscos y los volúmenes a extraer, los que sólo quedan como parte de la memoria oral de algunos lugares, como Cucao:

La gente, para que no se perdieran los mariscos, nunca dejaban que se boten los perros al agua, eso era como mal mirado. No le gustaba que marisquen las mujeres embarazadas tampoco, porque así se perdían los mariscos. Eran muy supersticiosos. En arrastrar el canasto tampoco le permitían o entrar con bolsas no, puro canasto. Dicen ahora que tanto que han cambiado, traen cosas diferentes, que entran fierros, porque esas cosas los (quiñes) traen fierro, y por eso dicen, decían los más antiguos [...] porque ahora poco va quedando de esa gente. 
Las prescripciones normativas de carácter religioso ritual regulan la relación entre las poblaciones humanas y no humanas, de modo que el comportamiento de una influye en la otra. Y que la gente mariscaba hincado de rodillas todo eso, todo dice que se pierde, el mar se enoja, la Huenchula, o la vieja [...] la vieja se enoja porque no había que arrodillarse, hincarse no.

El pescador recolector de orilla era igualmente objeto de protecciones rituales que atraían la suerte. "Mi madre decía", cuenta la Presidenta de la Comunidad Indígena La Montaña. Ya van a ir a buscar chicos decía el laurel (Laurelia sempervirens) y el chaumán (Pseudopanax laetevirens) y lo ponían encima del fogón, y eso cuando ya empezaba a acalorarse ya largaba el olorcito, y entonces ella lo que hacía iba a buscar la lienza de mi papá, y lo envolvía en una bolsa, bien envuelto que se evaporice todo eso, y lo tenía hasta la hora que salía a la pesca, y cuando quería salir a la pesca él, mi papá, mi mamá le dejaba uno o dos ganchitos de laurel y chaumán, y le empezaba a hacer con esas mismas ramitas por su cuerpo, todo encima de su ropa, todo, todo. Después le iba bien.

La técnica no deja de ser evocativa de la empleada para conservar los mariscos: el curantear, técnica que adquiere un sentido reverso cuando se trata de proteger al pescador que sale a procurar los productos del mar. Hoy en día el treputo, es aplicado de forma individual con redes y lienzas, usando principalmente ramas de chaumán (Pseudopanax laetevirens) sobre brasas calientes. Cuando comienza a liberarse abundante humo, los aparejos de pesca son azotados o puestos sobre esta estructura. Subyace en esta práctica el encuentro de mar y tierra bajo la una forma ritualizada donde la quema del chaumán o sauco del diablo permite proteger sea al pescador, sea a los instrumentos de su oficio. De modo inverso, el sargazo (Macrocystis pyrifera), es usada bajo la forma de cataplasma para paliar los dolores del reumatismo, dolencia que puede ser en este contexto asociada a las actividades de pesca o recolección de orilla. La relación especular, en este sentido, es sacralizada a través del ejercicio de este y otros ritos.

Una mención especial, entre los ritos asociados a la pesca, merece la muerte por ahogo, la cual convierte el grito de la victima en el aúmen que avisa los cambios del clima y del mar. Cuando uno muere en el agua, entonces dice que muere desesperado, y ahí grita. Y decían que después, como murieron así, ellos gritaban, ellos eso decían: 'Se escuchó un aúmen'. A eso le decían aúmen, al grito. Y eso cuando si lo escuchaban decían: 'Ah no, va a cambiar el tiempo'. Mi abuelita siempre lo escuchaba eso, y me decía; 'Va a cambiar el tiempo'. Yo le decía; 'Por qué abuelita?' Me decía: 'No, porque ayer en la tarde, estaba entrando leñita y empecé a escuchar el aúmen'. Y nosotros como éramos niños nos reíamos no mas, ¿qué sabíamos de aúmen? Nada.

Las prácticas asociativas y la distribución de las tareas.

La integración de las actividades costeras permitía, según los relatos recogidos, distribuir la carga de trabajo entre los sexos y las generaciones de acuerdo a la estacionalidad y a una vasta diversidad de recursos. Asimismo, la integración se fortalecía con el comercio, el trueque y la navegación. Dadas las características de la población y su tecnología no se producía ni la intensificación ni la sobre explotación de algún recurso en particular, lográndose con ello la reproducción de las especies. En esos años vivíamos de la siembra y de la marisca. La integración de estas actividades permitía asegurar la provisión cotidiana de los recursos. Casi todas mis comidas eran pescado y mariscos, porque ahí donde estábamos no teníamos ovejas, no teníamos vacunos [...] ¡Porque tanta calidad de mariscos! Que los caracoles, que la almeja (Venus antiqua), que las navajuelas (Tagelus dombeii), huepos (Ensis macha) [...] Teníamos ese bote bongo, y tenía la finá de mi mamá [...] un caballo, así que con ese caballo nosotros íbamos a la marisca y ella lo salía a vender quizás dónde, según un residente de Guaipulli.

La actividad de orilla era una actividad colectiva, una escena donde cada actor encontraba su papel, asegurándose de ese modo la cohesión social. En la memoria de una residente la playa se convertía en centro de una intensa vida social asociada a la organización de la faena de pesca: En el varadero se juntaban muchísimos pescadores. Y yo me iba y se hacía una fogata grande, estábamos diez en la noche ... todos se reunían e iban a poner la carnada al anzuelo, así que nosotros en eso nos preocupábamos de hacer el fuego para eso, era bien bonito antiguamente.

La regulación ritual de la actividad recolectora y pesquera respondía a los vaivenes del mar y de 
las poblaciones de mariscos, algas y peces. El mar es objeto de respeto y el trabajo se regulaba según fuese su comportamiento. Tú ves que el mar a veces esta calmo, a veces está malo, y cuando esta malo nosotros nadie se mete a pescar ni a mariscar, ya pueden ser mareas buenas, que digan marea (pilkan) que le llamamos nosotros a la luna llena, o luna nueva, pero nadie se tira a mariscar con el mar malo, todos respetamos eso que el mar está malo, asegura una residente de Palihue. Dada la naturaleza impredecible de la mar, el acceso comunitario a los recursos respondía de modo flexible a las posibilidades de un adecuado aprovisionamiento de la población, sin arriesgar la reproducción de las especies que le servían de sustento.

Los corrales de pesca permitían el acceso a un abundante recurso que era distribuido a toda la comunidad, si bien cada corral pertenecía a una familia en particular. Las familias que no poseían acceso podían acercarse a observar las faenas. Eran los collis y era habitual que ante tanta abundancia el dueño les permitiese entrar a la estructura y llevarse lo que pudiesen. De esta forma, todos los habitantes de la costa, y aun los del interior, podían consumir pescado sin limitaciones.

\section{EL IMPACTO SOBRE LOS PATRONES CONSUETUDINARIOS Y SUS MANIFESTACIONES LOCALES.}

Las transformaciones ocurridas hacia fines del siglo veinte gravitan de modo decisivo sobre el patrón de uso consuetudinario de los recursos marítimos y terrestres del litoral de Chiloé. Estas transformaciones se asocian directamente con la apertura de mercados que movilizaron la fuerza de trabajo hacia la exportación de recursos del mar. La expansión en el cultivo de algas, el desarrollo pesquero y la industria del salmón -y actualmente la mitilicultura- han sido los principales agentes de las transformaciones vividas localmente. El impacto que estos procesos han tenido ha sido diferencial según las características de las localidades consideradas pero, en todos los casos, redunda en a lo menos los siguientes aspectos: una desvinculación creciente de los distintos componentes del modelo consuetudinario que hemos descrito; desplazamientos de las poblaciones tanto locales como extralocales, y empobrecimiento de los recursos del mar.
El principal impacto sobre el modelo consuetudinario fue la disociación mar-tierra, lo que constituía el núcleo fundamental del modelo. La separación ocurre bajo formas diversas. Por una parte, los movimientos de población determinan presiones inesperadas sobre los recursos locales. Luego, las modalidades de cooperación con respecto del uso del borde costero sufren igualmente el impacto. Ya no resulta posible generar vínculos cooperativos entre los que otrora fueran propietarios de corrales y quienes se allegan a sus costas. Por el contrario, bajo el nuevo escenario, lo que se impone es una fuerte tendencia a privatizar la relación con el medio y a encapsular las áreas dominadas bajo formas materiales y legales: el corral ya no se aplica a la pesca sino más bien a los seres humanos en cuanto a sus derechos de propiedad. El resultado de estos cambios se traduce en una dependencia creciente del trabajo asalariado, en importantes variaciones en la dieta alimenticia, en la cosmovisión y en un incremento de la conflictividad local, entre muchos otros aspectos, como refiere una vecina de Palihue:

Con las pesqueras, empezó a cambiar porque ya la gente empezó a irse a trabajar a las pesqueras, cuando hubo camino los empezaron a venir a buscar aquí mismo. La gente empezó a salir [...] buscando el trabajo de las pesqueras, porque aquí antes había harta gente, y yo creo que la mitad de la gente que había se ha ido para Castro, a Chonchi en busca de mejoras de trabajo. Porque ahora no se puede hacer, ya no hay las machas suficientes para que diga, ya no se hace curanto, ya no se seca, ya no se ahuma esa macha, no lo salen a vender.

La transformaciones ocurridas en las últimas décadas se manifiesta en una pérdida de control sobre los sistemas de aprovisionamiento local, especialmente de aquellos que constituyen la dieta asociada al modelo consuetudinario. El agotamiento de recursos y la dependencia creciente del dinero llevan a la familia chilota hacia el supermercado: Es que ahora las costumbres antiguas eso ya casi no existen, ahora se come más la carne, se come el pollo, se comen las cosas más congeladas, y antes no era así [...] cuando nosotros vinimos no había nadie en la playa, poquita gente, señalan dos residentes antiguos de la isla.

Los cambios de la dieta reflejan esta ruptura que se entiende como crucial en la articulación del 
modo de producción local, esto es, la enajenación del mar con respecto a una cultura que ejercía sus oficios campesinos en el medio marítimo: "Uno como chilote está medio olvidado de los mariscos, si no encuentra nada, se lo han sacado todo ya ... Como se dice el mar es de todos ... así que pa los campesinos como somos nosotros no pescamos nada ... por eso que vienen barriendo ... ya no respetan lo que es la crianza, eso lo llevan todo no más ... ¿No piensan para más tarde? ¿para la familia que viene detrás de ellos?, porque llevan toda la crianza, entonces el mar lo van colando", reclama un residente de la isla Laitec.

\section{Empobrecimiento y contaminación}

de los recursos del mar

En el resto del archipiélago abundan relatos que acusan malas prácticas: Antes había mucho marisco, ahora no hay nada, señala un pescador de Coñimó: Yo me recuerdo no hace muchos años que todo lo que produce el mar había abundante. Pero ahora todos los recursos están perdiéndos. La extracción de especies de menor talla, que son aceptados y solicitados por la industria conservera, no pasa desapercibida: Antes habían recursos para mariscar, habían lo que uno quería iba a buscar, $y$ en un rato uno iba a buscar una bolsa o media bolsa de almejas, loyas, caracoles, todas esas cuestiones. Ahora lo sacaron todo los buzos, con altas mareas, con mar lleno, salen hasta tierra, $y$ ahí sacan todo lo que hay, no hay ni un respeto.

La salmonicultura es asociada directamente con la contaminación de los bancos naturales y costas, afectando recursos que antes eran abundantes

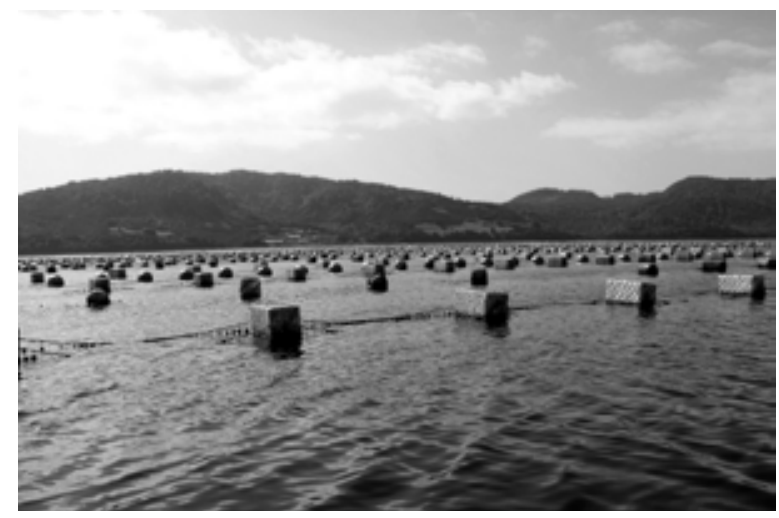

(Figura 4 Der.). Señalan que en el lugar donde hay salmonera ya no hay navajuela ni otros recursos, advierte un residente de la isla Laitec. Respecto del luche asegura que las piedras "quedaron así, blancas". Desde hace unos siete años, aseguran, es el excremento que se va botando de los pescados, la salmonera, va quedando todo en el fondo, entonces viene las mareas y lo echa por la costa.

La masificación de infraestructura flotante de la miticultura por otro lado provoca, como problemas no esperados, la obstaculización de zonas de tránsito tradicionales y zonas de pesca, saturando el mar con balsas y colectores (Figura 4 Izq.). Hoy en día la normativa exige la utilización de balsas de plástico resistentes. Sin embargo, en la historia reciente generaron enormes volúmenes, junto a la salmonicultura, de basura flotante (principalmente poliestireno o plumavit).

Las algas, recurso vital para miles de familias en tiempos de verano, son igualmente afectadas por la extracción excesiva efectuada por buzos ajenos a sus localidades: Con los buzos que van a sacar la luga donde la gente lo va a sacar a pata, luga pateá le dicen, y ahí se van los buzos con la hora de mar lleno, cuando sube un poco [...] y se van a robarle a la gente, porque ellos pueden trabajar un poco más hondo, entonces la gente igual se subleva y va y procede mal, aunque no tienen ninguna documentación [...] pero ellos a su manera defiende sus recursos, según señala el citado residente de la isla Laitec.

\section{Competencia y distanciamiento de los recursos}

El empobrecimiento de los recursos producido por la voluminosa presencia de competidores ex-

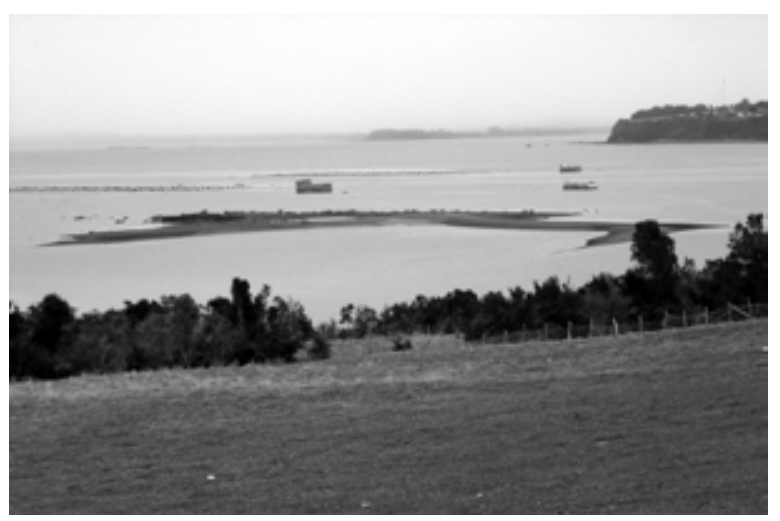

Fig. 4. Izquierda: Saturación de espacio marino por cultivos de mitílidos, canal Coldita, comuna de Quellón (Fotografía: R. Alvarez 2009). Derecha: Banco natural de mariscos afectado por salmonicultura (al fondo), lo que ha causado perjuicios en dos comunidades indígenas ribereñas. Punta Chilen-Coñimó, comuna de Ancud (Fotografía: R. Álvarez 2009). 
ternos promueve aún más la separación del mundo marino, lo que acarrea consigo nuevas condiciones de operación para los actores locales. Hay en ellos un proceso de especialización en la faena pesquera $y$ se ven enfrentados a una mayor competencia con actores externos, primero, y, luego, entre los propios residentes. La escasez creada comienza a tensionar las relaciones internas a nivel comunitario. La especialización en la actividad marina trae aparejados problemas que en la economía del litoral no estaban documentados: Nosotros como buzos, como pescadores, como sindicatos, somos muy desunidos, estamos viendo la misma gente que, nosotros también, por parte mía me involucro de ser culpable, porque estamos dejando que la gente está sacando las semillas.

Por otra parte, la sobreexplotación lleva a que los recursos comiencen a distanciarse de la costa $y$, como resultado de ello, se requiere de un mayor esfuerzo y de una mayor inversión en la navegación: Cada día, así como el pescado se ha ido corriendo hemos tenido que de alguna manera haciendo nosotros embarcaciones que sean más rápidas, que sean más grandes. El pescado tiene sus aposentos y eso se pelea, se busca, según explica el Longko de la comunidad Coñimó-Lamecura. Antes, no era necesario irse lejos, por acá no más alrededor [...] pero ahora se ha ido el pescado, concluye una vecina de la isla de Laitec.

El alejamiento gradual de los recursos implica no sólo una mayor competencia por los espacios y un gasto en combustible y tiempos mayores. También hay en este proceso una desvinculación y una estratificación social. No sólo la especialización es

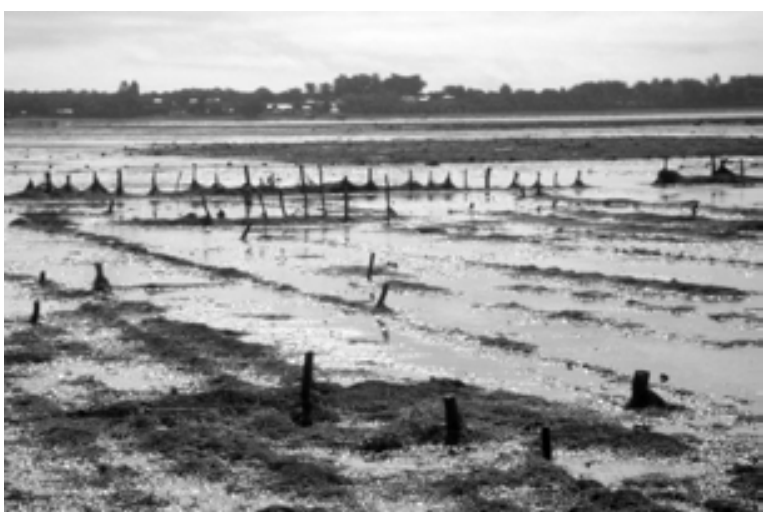

inevitable sino que también las posibilidades de operar en el medio quedan restringidas a embarcaciones mejor equipadas.

\section{Privatización de los espacios}

Un proceso paralelo ha ocurrido en relación a la recolección y cultivo de las algas. Igualmente estimulado por un mercado exportador, el pelillo (Gracilaria spp.) sigue siendo por excelencia el alga más utilizada. Actualmente es sembrada en diversas zonas costeras del territorio insular de Chiloé. Si bien el auge de dicha actividad se dio en la década de los ochenta, hoy en día sigue siendo un ingreso importante para cientos de familias. Las consecuencias que comienzan a evidenciarse: de una parte, los actores locales comienzan a disputar espacios que antaño eran comunitarios, $y$, al hacerlo, por la otra, se comienza a erguir una verdadera barrera entre el mar y la tierra (Figura 5).

En ambos casos y a pesar de su informalidad, se trata de una actividad de subsistencia esencial para familias ribereñas y campesinos que viven tierra adentro. De hecho, sin esta actividad la migración urbano-rural sería aún más acelerada.

La distribución de la bahía de Caulín constituye un ejemplo especialmente relevante para ilustrar este proceso. La playa digamos no está libre, dice una residente. Por ejemplo nosotros, tomamos un pedacito y plantamos alga ahí y todas tenemos un pedacito, la playa esta toda así. No está legalizado, no está con papeles, pero también sería penca [malo] llegar y tomar esos pedazos que se están trabajando de años.

Fig. 5. Dos modalidades en la explotación informal del alga pelillo: Izquierda: Distribución de espacios para siembra y extracción bajo acuerdos locales, Caulín, comuna de Ancud (Fotografía: R. Álvarez 2009). Derecha: Putemún, comuna de Castro, espacio costero donde conjugan pelilleros de distintas procedencias sin distribución de espacios ni cuotas (Fotografía: R. Álvarez 2010).

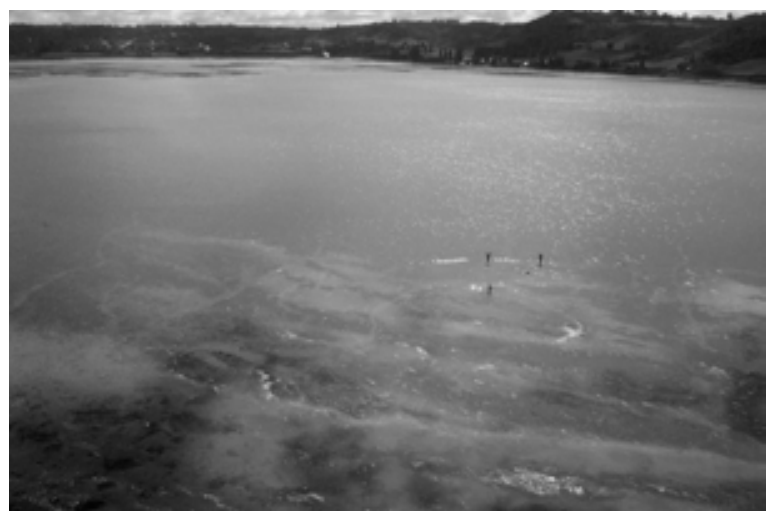


Los cultivos de algas no sólo interfieren las relaciones sociales a nivel comunitario sino que también comienzan a yuxtaponerse con otras actividades productivas, y con ello, asfixian los espacios de trabajo para otras personas y áreas de reproducción y alimentación de otras especies. La distribución consuetudinaria de la tarea productiva, adecuada a las dinámicas poblacionales de determinados recursos, entra en crisis y con ello, además, se arriesga la conservación de la naturaleza.

El cultivo excesivo afecta la reproducción de los mariscos, perjudicando a quienes viven de su recolección, y a las aves migratorias que usan la zona como lugar de paso y alimentación. Ese es el problema de las personas que tienen plantado todo, que siguen plantando para abajo y se está perdiendo la almeja (Venus antiqua). Están plantando encima de los bancos de almeja, se queja un miembro de la comunidad indígena de Wente Caulín. Ya no se usa eso de que la persona a pie iba a buscar un saco, dos sacos de almejas (Venus antiqua), porque la almeja se murió por el exceso de algas que le quita el oxígeno.

\section{Áreas de manejo}

Las áreas de manejo de los recursos bentónicos (AMERB), es una modalidad que el Estado chileno ha dispuesto a fin de consagrar el manejo adecuado de los recursos, asignadas a un sindicato de pescadores, a fin de hacer una explotación sustentable de los mariscos. La figura es evocativa de las modalidades de vinculación tierra-mar en el mundo chilote. De ahí que resulte conveniente examinar algunos efectos de su aplicación, tal cual se describe para la localidad de Guapilacuy. Allí, según explica uno de sus residentes, la implantación del área ha permito proteger las especies marinas. Hallamos, dice, un banco de centollas, tienen comedero, porque está protegido. ¿Qué ocurre con las áreas que no están protegidas? Están más explotadas, es que viene gente de otros lados se nos vienen a meter las lanchas de otros lados, ¿Usted cree que si eso no hubiese estado protegido por nosotros iba a haber algo? No iba a haber nada porque se iban a meter otras personas.

Las áreas de manejo, no obstante constituye resguardos para las especies marinas, requieren complementarse con las actividades de tierra. De lo contrario se insertan en las dinámicas depredadoras ya descritas. De hecho, el concepto pierde parte de su poder - desde la perspectiva consuetudinaria toda vez que encapsula bajo un régimen privado de acceso al recurso marítimo.

Por otra parte, la protección de las áreas, al radicarse exclusivamente en la figura de los pescadores artesanales, se debilita. La desvinculación del Estado respecto de esta tarea posibilita la acción de personas que, provenientes de otros sectores, incursionen en las áreas. El daño causado es notorio: Ahora tenemos un parque de cultivo, (lo) tenemos en Pudeto. No nos ha dado resultado porque nos roban. Teníamos ostra japonesa después se sembró algas, también en la noche lo iban a robar, reclama un residente de Guapilacuy.

\section{POTENCIALIDADES Y LIMITACIONES}

De mantenerse las tendencias actuales, las posibilidades de revertir la situación descrita son mínimas. Sin embargo, el escenario cambia si se lo analiza bajo el prisma histórico provisto por el modelo consuetudinario, el que sienta un precedente importante para la planificación del uso sustentable de los recursos. Este precedente se apoya en ciertos principios rectores de lo que fuera la economía local y que hoy pueden ser desarrollados a través del fomento de proyectos e iniciativas que incorporen estas orientaciones. En este modelo hay tres claves que se deben considerar a fin de lograr una adecuada gestión de los recursos litorales. Estos son: (i) la vinculación tierra-mar; (ii) la flexibilidad en el acceso a los recursos, y (iii) el patrón de asociatividad.

Dada la naturaleza especular de la relación tierra-mar, una propuesta de intervención debe considerar que cualquier iniciativa asociada a un término tiene un correlato en el otro término de la relación. Los corrales de pesca constituyen una imagen refleja del mundo de la agricultura y se adentran en él a través del intercambio y el trueque.

Esto significa que los proyectos de desarrollo pesquero, por ejemplo, o la introducción de especies cultivables, debieran traer aparejados apoyos que necesariamente redunden en un mejor aprovechamiento de los recursos del suelo, y a la inversa. Las modalidades de articulación trabajo-recurso natural permiten neutralizar los efectos nocivos de la intensi- 
ficación productiva en los recursos de mayor valor de mercado. A la vez, son justamente tales recursos los que complementan la dieta que, bajo las condiciones actuales, se ve peligrosamente alterada.

La flexibilidad en el acceso a los recursos es otra de las características medulares del modelo consuetudinario. Cuando se pregunta a una residente cómo se van a organizar a futuro, ella responde: En común creo porque no es la idea el tener cada uno su espacio tampoco. Porque se sabe que de repente aquí no hay mariscos y puede que salga en Rahue, y no hay en Rahue puede salir en Guentemo. La lógica de esta respuesta sintetiza con elocuencia la modalidad local de resolver los temas productivos. Las áreas de manejo de recursos bentónicos han sido una respuesta interesante para avanzar en la vinculación tierra-mar pero, como se ha visto, la rigidez con que están planteadas limita su potencial. La población local históricamente ha optado por la flexibilidad en el acceso, en el entendido que la práctica que ha demostrado su eficiencia ha sido la adaptación recíproca de las poblaciones humanas y no humanas. Esta flexibilidad se proyecta no sólo en el acceso sino también en la diversificación de la base productiva de la economía local. De aquí que, asociado con el fomento de iniciativas vinculantes del mar y la tierra, las propuestas de desarrollo debieran, si se atienen al modelo histórico, disponer como herramienta de trabajo la pluriactividad, fomentando no sólo la diversificación de la base productiva sino que la multiplicación de experiencias de trueque e intercambio que a nivel local resolvían la adecuada distribución de los recursos. Además, debieran considerar como válidas las prácticas que son informales toda vez que se sustenten en una raigambre histórica. No se puede excluir o sancionar de un espacio costero a miles de campesinos y ribereños locales que extraen pelillo sólo porque no se han organizado bajo figuras legales de administración de espacios costeros.

El tercer componente del modelo tradicional es la presencia de los collis. Esta institución local constituye una referencia significativa y con presencia en la memoria del colectivo de formas culturalmente apropiadas de asociatividad. La mirada actual no puede desentenderse del hecho de estar poblado el mundo costero de Chiloé por comunidades y empresas de las más variadas proveniencias cuyo libre tránsito ha sido lo que más ha perjudicado a los lugareños. En el caso de los collis, su presencia se apoyaba en la seguridad alimentaria de los residentes propietarios - en términos tradicionales - de los corrales de pesca, esto es, de la relación fundante entre mar y tierra.

\section{CONCLUSIONES}

La economía litoral de Chiloé ofrece una imagen especular del mundo de la producción donde el tránsito de tierra a mar constituye el puente que permitió aglutinar las actividades productivas de modo tal de asegurar un suministro permanente de recursos a la par que facilitar la reproducción de las especies con las que las comunidades se relacionaban. El modelo consuetudinario se encarnaba en el complejo pesquero dominado por los corrales y los senderos que la unían a tierra. Este complejo, complementado por la relación de la pesca, las algas y los mariscos, representaba un medio de regulación en el acceso a los recursos a la vez que facilitaba una conveniente distribución de los mismos hacia el interior. La distribución de la tarea tanto en lo estacional como en lo social garantizaba la existencia de una base productiva diversificada que, a través de eslabonamientos hacia el interior, hacía posible la continuidad de una economía basada en los valores de uso, en el trueque y en el comercio menor.

La cultura litoral de Chiloé se constituyó a partir no de la separación sino de la conjunción de tierra y mar, regulándose los intercambios de productos de un contexto a otro a través de mediaciones técno instrumentales, sociales y rituales. Como se ha señalado, esta relación está marcada por el carácter especular de tales intercambios y se invierten importantes esfuerzos por proteger ritualmente este carácter. El pescador y sus instrumentos de pesca son cuidadosamente protegidos a través del chaumán y el laurel, por ejemplo. De modo análogo, las invocaciones religiosas marcan el tránsito de un mundo a otro y, en la dimensión técno instrumental, el curanteo constituye un medio de procesamiento de las especies marinas para su distribución por la vía del comercio y del trueque en el medio terrestre.

$\mathrm{El}$ andamiaje, sobre el que se constituye el modelo consuetudinario se ve profundamente trastrocado con la incorporación de los recursos 
al mercado. En lo sustantivo, se puede afirmar que este proceso se encarna en la disociación del vínculo fundante mar-tierra que diera sentido a la experiencia de las comunidades del litoral de Chiloé. Esta separación induce una zonificación con una marcada separación de papeles que tiene, entre otros, los efectos de invertir el sentido de cercar ya no las aguas para obtener de ellas los productos para la subsistencia sino a las personas y empresas dentro de sus propiedades. Efectos colaterales de este giro se producen en términos de la territorialización de las relaciones y de la consecuente pugna por el acceso diferencial a los recursos, amen de la intensificación de los procesos productivos y el distanciamiento y agotamiento de los recursos.

Las posibilidades de revertir estos procesos se fundan en un reconocimiento del potencial radicado en el modelo consuetudinario y ello pasa por dos aspectos principales: la reconstitución de la relación mar-tierra y la flexibilidad en el acceso a los recursos. En palabras de una informante, si son las comunidades las que libremente se relacionan con su medio marítimo y terrestre hay más posibilidades de lograr el balance que se procura establecer entre actividades productivas y los recursos locales siempre y cuando no se disocien las relaciones tierra-mar. La experiencia de las comunidades litorales de Chiloé sugiere, desde esta perspectiva, más que la tragedia de los comunes, la tragedia de las mentalidades que separan lo que de otro modo está unido, lo que fácilmente conduce a la bancarrota ambiental.

\section{BIBLIOGRAFÍA}

ALDUNATE, C. 1996. Mapuche: gente de la tierra. En: Etnografía. Sociedades indígenas contemporáneas y su ideología, J. Hidalgo, V. Schiappacasse, H. Niemeyer, C. Aldunate y P. Mege editores. pp. 111-134. Editorial Andrés Bello, Santiago.

ÁLVAREZ, R. Y M. NAVARRO 2010. Diagnósticos sobre usos consuetudinarios costeros para ocho comunidades Williche de Chiloé. WWF, Centro Ballena Azul, Valdivia.

ÁlVAREZ, R., D. MUNITA, J. FREDES Y R. MERA 2008. Corrales de pesca en Chiloé. Editorial América, Valdivia.

ASPILlAGA, E., C. OCAMPO, J. OLIVARES, B. ARENSBURG Y J. MEYER 1995. Una visita a los canoeros de Quetalmahue. Revista Museos 20:18-20.
BEDOYA, E. Y S. MARTÍNEZ 2000. De la economía política: Balance global del ecomarxismo y la crítica al desarrollo. En: Antropología del desarrollo. Teoría y estudios etnográficos en América Latina, A. Viola editora. pp. 129-168. Ediciones Paidós, Barcelona.

BENNET, J. 2010. Vibrant matter. A political ecology of things. Duke University Press, Durham.

CÁRDENAS, R., D. MONTIEL Y G. HALL 1991. Los chono y los veliche de Chiloé. Editorial Olimpo, Santiago.

CAVADA, F. 1914. Chiloé y los Chilotes. Editorial Universitaria, Santiago.

DURRENBERGER, E. PAUL Y GÍSLI PÁLSSON 1987a. Ownership at Sea: Territories and Access to Sea Resources. American Ethnologist, 14(3): 508-522.

ESCOBAR, A. 1999. 'After nature': Steps to an anti-essentialist political ecology. Current Anthropology 40: 1-30.

FIGUEROA, J. 2005. Informe Sectorial Pesquero Artesanal. Sernapesca, Santiago.

GAETE, N., X. NAVARRO, F. CONSTANTINESCU, R. MERA, D. SELLES, M. E. SOLARI, L. VARGAS, D. OLIVA Y L. DURÁN 2004. Una mirada al modo de vida canoero del mar interior desde Piedra Azul. Chungara. Vol. Especial. Actas del XV Congreso Nacional de Arqueología Chilena: 333-346. Arica.

GONZÁLEZ DE AGÜERO, P. 1791. Descripción Historial de la provincial y Archipiélago de Chiloé en el Reyno de Chile. Cano. Imprenta de Don Benito, Madrid.

HARDIN, G. 1968. The tragedy of the commons. Science 162: $1243-1248$.

HUCKE-GAETE, R., R. ÁlVAREZ, M. NAVARRO, J. RUIZ, P. LO MORO Y A. FARÍAS 2010. Investigación para Desarrollo de Área Marina Costera Protegida ChiloéPalena-Guaitecas. Informe Final de estudio financiado por FNDR - BID TURISMO Cód. BIP N 30040215-0, Gobierno Regional de Los Lagos. Unidad técnica mandante: CONAMA. Ejecutado por Universidad Austral de Chile. 800 pp. [Disponible en www.conama.cl].

INGOLD, T. 2011. Being Alive: Essays on Movements, Knowledge and description. Routledge, Londres.

LATOUR, B. 2001. Un colectivo de humanos y no humanos. Un recorrido por el laberinto de Dédalo. En: La esperanza de Pandora. Ensayos acerca de la realidad de los estudios de la ciencia. pp 208-259. Grijalbo, Barcelona.

LEFF, E. 2003. Globalización, racionalidad ambiental y desarrollo sustentable. La Guía Ambiental. México: Unión de Grupos Ambientalistas. (http://www.union.org.mx/ publicaciones/guia/poblacionyambiente/globalizacion. htm; consultado el 29 de enero de 2010). 
LEGOUPIL, D. 2005. Recolectores de moluscos tempranos en el sureste de la isla de Chiloé: una primera mirada. Magallania, 33 (1): 51-61.

MENGHIN, O. 1962. Estudios de Prehistoria Araucana. Studia Prehistórica II. Centro Argentino de Estudios Prehistóricos, Buenos Aires.

O'CONNOR, J. 1998. Natural Causes: Essays in Ecological Marxism. Guilford, Nueva York.

OCAMPO, C. Y P. RIVAS 2004. Poblamiento temprano de los extremos geográficos de los canales patagónicos: Isla de Chiloé e Isla Navarino. Chungará Vol. Esp.:317-331.

OLIVARES, MIGUEL DE. 1874. Historia de la Compañía de Jesús en Chile. Imprenta Andrés Bello, Santiago.

PORTER, C. 1995. GUA-010, un sitio costero erosionado en una zona sísmica activa. Actas del XII Congreso Nacional de Arqueología Chilena, tomo 2: 81-88. Temuco.

RIBERA, L. 1897. Discurso que hace el alferez don Lázaro de Ribera, injeniero delineador, sobre la Provincia de Chiloé por órden del Supremo Gobierno de Lima, desde esta misma ciudad en agosto de 1782. En: Cinco relaciones jeográficas e hidrográficas que interesan a Chile. Anrique, N. editor. Pp. 1-67. Imprenta Elzeviriana, Santiago.

RIVAS, P., C. OCAMPO Y E. ASPILLAGA 2000. Antecedentes del sitio arqueológico Puente Quilo 1 (Ancud 031). Informe proyecto La Humanidad Anterior. MS.
SERNAPESCA. 2001. Anuario Estadístico de Pesca. Santiago. (http://www.sernapesca.cl/index.php?option=com_re mository\&Itemid $=54 \&$ func $=$ select $\& \mathrm{id}=2$; consultado durante marzo, abril 2010).

2008. Anuario Estadístico de Pesca. Santiago. (http:// www.sernapesca.cl/index.php?option=com_remositor $y \&$ Itemid $=54 \&$ func $=$ select $\& \mathrm{id}=2$; consultado durante marzo, abril 2010).

2007. Anuario Estadístico de Pesca. Santiago. (http:// www.sernapesca.cl/index.php?option $=$ com_remositor $y \&$ Itemid $=54 \&$ func $=$ select $\& \mathrm{id}=2$; consultado durante marzo, abril 2010).

SCHMINK M. Y CH. WOOD 1987. The political ecology of Amazonia. En: Lands at risk in the Third World: Local level perspectives. P.D. Little, y M.M. Horowitz, editores. Pp. 38-57. Westview Press, Boulder.

VIVAR, G. 1970 [1558]. Crónica y relación copiosa y verdadera de los Reinos de Chile. Editado por Leopoldo Saez-Godoy. Bibliotheca Ibero-Americana, Colloquium verlag, Berlin.

WEBER, A. 1903. Chiloé, su estado actual, su colonización, su porvenir. Imprenta Mejía, Santiago.

WEERATUNGE, N., A. AGRAWAL, S. GURURANI Y K. MILTON 2000. Nature, harmony, and the Kaliyugaya: Global/local discourses on the human-environment relationship / Comments / Reply. Current Anthropology, 41(2): 249-269. 
